\title{
Research on Evaluation of Regional Economic Competitiveness Based on Fuzzy Analytic Hierarchy Process
}

\author{
Youliang Zhou ${ }^{1}$, Zhuo $\mathrm{Lu}^{2}$ \\ ${ }^{1}$ Zhaoqing Institute of Economic Society, History and Culture, Zhaoqing University, Zhaoqing, 526061, China \\ ${ }^{2}$ City University of Macau Faculty of Business, Macau, 999078, China
}

\begin{abstract}
The evaluation of regional economic competitiveness plays an important role in the healthy development of regional economy. Based on the evaluation of current regional economic competitiveness, this paper proposes the use of fuzzy analytic hierarchy process to evaluate the regional economic competitiveness, and based on the fuzzy analytic hierarchy process, it faces the regional economic competitiveness evaluation indicators from the economic, social and ecological levels. The system is constructed and the specific method of regional economic competitiveness evaluation based on fuzzy analytic hierarchy process is studied.
\end{abstract}

Keywords: regional economic competitiveness; evaluation; fuzzy analytic analysis; research

\section{Introduction}

Under the background of the accelerating globalization process, the degree of regional economic integration has also deepened, and the development of regional economy has become a strategic goal that governments at all levels have paid more and more attention to. From the essence of regional development, it mainly obtains more absolute advantages and comparative advantages through continuous competition, and continuously constructs new competitive advantages in order to re-establish its competitive advantage or construct new competitive advantages. The development of regional economy shows outstanding diversity and complexity, and regional economic competitiveness also has multiple levels of complex meaning. For regional competitiveness, there are hierarchy process (AHP) was proposed in the 1980s as a multi-objective decision-making method for dealing with non-quantitative events. In the evaluation of multiple indicators and ambiguous schemes, more satisfactory evaluation results can be obtained. Studying the evaluation of regional economic competitiveness through fuzzy analytic hierarchy process can help to deeply explore the factors affecting regional economic competitiveness, understand the different roles of different factors, and facilitate the full play of existing competitive advantages in regional economic development. Improvements to disadvantages and deficiencies can also provide targeted management decision-making basis for regional managers.

The study on the evaluation of regional economic competitiveness began in the United States. As early as 1978, the US Bureau of Technology Evaluation conducted research on US competitiveness. Since then, this competitiveness research has gradually penetrated into the field of regional economic competitiveness research, and has achieved many theoretical

Copyright (C) 2019 by author(s) and Frontier Scientific Research Publishing Inc.

This work is licensed under the Creative Commons Attribution International License (CC BY 4.0).

http://creativecommons.org/licenses/by/4.0/ 
and empirical research results. Taken together, these studies focus on regional economic competition mechanisms and the factors affecting regional economic competitiveness. In the specific regional economic competitiveness evaluation methods, there are mainly diamond models. The model involves four basic determinants, namely, advanced factors, market demand, and industrial clusters and corporate strategies. In addition, the more influential model of urban competitiveness, which divides the evaluation factors of regional economic competitiveness into four aspects, one is economic structure, the other is regional endowment, the third is human resources, and the fourth is institutional environment. However, these evaluation models are generally broad in the coverage of the competitiveness rating index system. It is difficult to obtain soft indicators, and a multi-layer measurement model has not been established in the evaluation of overall competitiveness. The evaluation results are not specific enough and objective .

\section{Evaluation of Regional Economic Competitiveness Based on Fuzzy Analytic Hierarchy}

\section{Process}

2.1Fuzzy analytic hierarchy process

In the 1970s, Professor Saaty proposed fuzzy AHP, which is a multi-objective decision-making method for dealing with non-quantitative events. The key step of the fuzzy analytic hierarchy process is to construct the judgment matrix. The quantification is usually applied to the 1-9 scale. Sometimes, because the decision makers have different aspects in the understanding of things, and the complexity of the objective things themselves, it will lead to different decision makers have different preferences in decision-making objects, and the judgment matrix given by them is difficult to reflect in practice, leading to the emergence of "uncertainty". Therefore, for these objective "uncertainties", the fuzzy analytic hierarchy process is used to qualitatively describe the $0-1$ interval, and it can obtain more satisfactory results in the process of evaluating the scheme with multiple indicators.

2.2Determination of regional economic competitiveness evaluation index system

In the process of understanding and evaluating regional economic competitiveness, if we want to make the understanding and evaluation of regional economic competitiveness more correct, we should build the evaluation system based on the most fundamental characteristics of regional economic competitiveness. Only by firmly grasping its core characteristics and constructing the evaluation index system can the regional economic competitiveness evaluation be effectively distinguished from the evaluation of other regional economic capabilities, and a more correct understanding of regional economic competitiveness can be formed. Therefore, in the process of constructing the regional economic competitiveness evaluation index system, it is necessary to start from the core characteristics of its competitiveness, and establish a regional economic competitiveness evaluation index system based on core characteristics, so as to achieve regional economic competitiveness.

In the regional economic development, economic factors, social factors and ecological factors play an important role in the region. Therefore, the evaluation of regional economic competitiveness can be selected from the economic, social and ecological levels.

\subsection{Construction of regional economic competitiveness evaluation}

For the regional economic competitiveness evaluation system, it is composed of multiple elements. In the indicator system, each factor is relatively clear in development goals in a certain period of time, and can be quantified by certain values. For the difference in goal orientation, the elements can be divided, one is the extreme value of the element pursuit goal, and the other is the maximum value of the element pursuit goal. For the actual and target values of the feature, the result can be derived based on the transformation relationship, thereby reflecting the role of the element in the system. This result is also referred to as the factor efficacy factor and ECi is represented. The value of the value is generally between 0 
and 1 , and $\mathrm{ECi}=1$ in the most satisfactory state of the element target, and $\mathrm{ECi}=0$ in the worst state. The relation describing the pair is called the power function to represent Xi. Because the regional economic competitiveness cannot be fully explained by the single factor efficiency coefficient in terms of comprehensive development situation and state, it is necessary to establish a relational formula that takes all the power efficiency coefficients from the independent variables. Generally speaking, for this function, it will become a regional economic competitiveness coordination function, referred to as coordination degree (HD), and the value range is $0 \leq \mathrm{HD} \leq 1$ the larger the value, indicating that the regional economy is in overall competitiveness. The stronger the upper, the worse the worse.

For the elements of the regional economic competitiveness evaluation system, its actual performance value is $\mathrm{xi}$ $(\mathrm{i}=1,2,3 \ldots \mathrm{n})$. In the case of system stability, the factor index variable has upper and lower limits at the critical point,

respectively, $\quad \alpha_{i}, \quad \beta_{i}, \quad \alpha_{i} \leq x_{i} \leq \beta_{i}$. Based on the synergy theory, when the system is in a steady state, its state function belongs to a linear relationship. For the extreme point of the function, it is the critical point of the system stable region. At the same time, when the system is in a stable state, the slow relaxation variable will also produce certain changes, which will bring two effects to the system: one is positive and the other is negative. So, in the power function, as follows:

In the case of positive effect,

$$
E C\left(X_{i}\right)=\left(x_{i_{-}} \beta_{i}\right) /\left(\alpha_{i_{-}} \beta_{i}\right),\left(\alpha_{i \leq} x_{i \leq} \beta_{i}\right)
$$

In the case of negative power,

$$
\left.E C\left(X_{i}\right)_{=(} x_{i_{-}} \beta_{i}\right) /\left(\alpha_{i_{-}} \beta_{i}\right),\left(\alpha_{i} x_{i_{\leq}} \beta_{i}\right)
$$

In terms of the degree of coordination function, it is usually calculated in a weighted summation manner, namely:

$$
H D=\sum_{i=1}^{n} F_{i} \times E C\left(X_{i}\right) \quad \sum_{i=1}^{n} F_{i}=1
$$

Under different stages of development, there are certain differences in regional economic competitiveness.

\section{Conclusion}

Due to the diversity and complexity of regional economic development, it is necessary to carry out comprehensive evaluation and investigation based on regional characteristics for the improvement of regional economic competitiveness. The evaluation of regional economic competitiveness through fuzzy analytic hierarchy process can realize mathematical description and quantitative expression in complex decision-making thinking, help to clarify the strength of regional economic competitiveness, and find more suitable for regional economy in a scientific and rational way. A sustainable path to development.

\section{Conflicts of Interest}

The author declares no conflicts of interest regarding the publication of this paper.

\section{References}

[1] Pelinescu, E., Iordan, M., Chilian, N., et al. (2017). Regional Economic Competitiveness: The case of Romania, Working Papers, 106-108.

[2] Martin, R., Sunley, P. (2017). Competitiveness and Regional Economic Resilience, Chapters, 59-60.

[3] Luca, D. (2016). Votes and Regional Economic Growth: evidence from Turkey, World Development, 78, 477-495.

[4] Saaty, T. L. (1980). The Analytic Hierarchy Process: Planning, priority setting, resource Allocation. McGraw-Hill, NY, USA, The Analytic Hierarchy Process: Planning, Priority Setting, Resource Allocation. 
[5] Deller, S., Watson, P. (2016). Did Regional Economic Diversity Influence the Effects of the Great Recession, Economic Inquiry, 54(4), 188-189.

[6] Nail, P. R., Sznajd-Weron, K. (2016). The Diamond Model of Social Response within an Agent-based Approach, HSC Research Reports, 129(5), 1050-1054.

\section{Fund project:}

1. Scientific Research Fund Project of Zhaoqing University: Feasibility Analysis and Research on the Establishment of Special Cooperation Zone between Zhaoqing City and Hong Kong and Macao Region (201950).

2. Zhaoqing Education Development Institute Key Project: Research on the Countermeasures of Zhaoqing Vocational Education Serving the Development of County Economy (ZQJYY2019026). 